\title{
Vicarious PTG after Fireworks Trauma
}

\author{
Michael Galea \\ Department of Mental Health, Faculty of Health Sciences, University of Malta, Msida, Malta \\ Email: mgalea00@yahoo.com
}

How to cite this paper: Galea, M. (2017) Vicarious PTG after Fireworks Trauma. Psychology, 8, 2496-2515.

https://doi.org/10.4236/psych.2017.814158

Received: November 2, 2017

Accepted: December 22, 2017

Published: December 25, 2017

Copyright (C 2017 by author and Scientific Research Publishing Inc. This work is licensed under the Creative Commons Attribution International License (CC BY 4.0).

http://creativecommons.org/licenses/by/4.0/

\begin{abstract}
Studies about fireworks-related trauma are scarce. Research on other traumas indicates not only the negative reactions and consequences, but also some important positive experiences. This falls within the remit of post-traumatic growth. More complicated may be the possibility of growth through trauma experienced by another person. Vicarious posttraumatic growth refers to positive changes from vicarious or secondary traumatic exposure. In this study, we looked at the trauma experiences by relatives of victims of fireworks' explosions in Malta, and the potential growth that may have ensued. Method: By using Interpretative Phenomenological Analysis, we interviewed 8 individuals who met the inclusion criteria. Analysis of data was guided by the Smith method (1999). Results: Key themes highlighted in this study focused on participants' appreciation of the present, acceptance of reality (others \& events), and spiritual growth (sense of relatedness with a God and with others). These themes conform to Tedeschi and Calhoun theory of post-traumatic growth (2004).
\end{abstract}

\section{Keywords}

Vicarious Post-Traumatic Growth, Positive Changes, Fireworks Trauma, Holistic Wellbeing, Resilience

\section{Introduction}

Although research on vicarious trauma related to firework tragedies is scarce, a number of similar studies suggest a mixed bag of consequences. This includes positive experiences as well, besides the obvious negative impacts.

Positive experiences fall within the gamut of post-traumatic growth, whereby individuals may report positive changes in their personal life, not in the sense of happiness or some kind of satisfaction for what occurred, or for the people lost, but a new meaning-making personal experience was borne out of the tragedy.

In this study, we targeted a number of fairly recent fireworks tragedies in 
Malta, and their impact on victims' relatives.

Firework displays are considered an important element in the typical Maltese religious festa, celebrated mostly during summer weekends. In Malta, a Catholic nation with a population of less than half a million, each parish seeks to outdo its neighbors in a summer of passionate frenzy. According to an article in the local Times of Malta (14.08.2009), Maltese fireworks have been developing rapidly recently, with some localities using computerized systems to fire hundreds of colorful petards that characterize the nocturnal sky displays, against synchronized music. Some villages are using the same computerized system as those popular abroad, including at the New Year's Sydney Bridge show, in Australia. Enthusiasts start producing their fireworks from months before, dedicating long hours per week. While a number of enthusiasts earn a living by manufacturing fireworks, many others do it free of charge as a hobby. One evening's display can easily run in excess of $€ 50,000$ (almost USD 60,000) for large village festas. Each festa will have daytime and nighttime firework displays, spanning a number of days but intensifying closer to the feast day. Malta boasts more than 80 village festas, varying in degrees and costs. Such exhibitions present awe for thousands of tourists and locals alike, pure obsession for many enthusiasts (who manufacture it and/or follow it from one village to another), to noise and air pollution to many others, particularly the young and the elderly.

Obviously, all this comes at a price, and not just financially. Chemical expert Alfred Vella found that environmental contamination from fireworks is a nasty reality in Malta (Muscat, 2014). Although no specific data exists so far on this topic, it is a known fact that fireworks impact public health and cost the country millions of euros. It is no wonder then that an increasingly opposing body at such displays is beginning to be felt more than before.

The aim of this study was to explore the aftermath personal experiences of family members who lost relatives due to fireworks tragedies in Malta. According to a UK study of firework accidents between 1950 and 1977, it was found an accident rate of 0.0001 per year (The Malta Independent, 2012). If the same rate was translated locally, considering the size differences, Malta should have one accident every 250 years. Instead, in the past three decades alone, fireworks caused an average 2.3 fatal accidents per year! In the last 35 years, $37 \%$ of all deaths due to fireworks tragedies came from the island of Gozo, the region where this study has been conducted.

In fact, recent news reported that the stark tradition of having a tragic accident related to fireworks in Malta has been broken since 2013. There are currently 34 fireworks factories in Malta with more than 2000 involved full-time. Between 1981 and 2010 around 2 individuals annually lost their lives due to such accidents. Between 2010 and 2013, 9 died in 3 major related explosions (TVM news, 2017). It is pertinent to this study to highlight the psycho-social and holistic needs of relatives who experienced the trauma of significant others or individuals very close to them. Personal experiences emanating from psychotherapy, 
as well as feedback from nurses and health care professionals involved in this field, continuously point at the local gap to attend to these individuals' holistic demands. Through such research, such issues may hopefully be appropriately addressed.

\subsection{Post-Traumatic Growth (PTG) and Related Factors}

For ages, suffering and growth that results there from have been understood to be interrelated, as is clear in various religious beliefs (Pargament, 1997). Positive reactions following adverse and traumatic events have been labelled as "positive psychological changes" (McMillen et al., 1995), "flourishing” (Ryff \& Singer, 1998), "stress related growth" (Park et al., 1996), and others.

Tedeschi and Calhoun prefer the metaphor of "seismic event" instead of "traumatic event" since PTG is possible only if the event has had a tremendous impact, or at least must be challenging enough to set in motion the specific mechanisms of cognitive processing indispensable for growth. The model of PTG is built on Lazarus' Cognitive-Motivational-Relational theory of stress.

The PTG posits that traumatic events serve as huge challenges to one's pretrauma schemas and worldview by shattering one's beliefs, goals and life's general assumptions. Calhoun and Tedeschi (2006) stress that schema restructuring, being the ability to find meaning from traumatic experiences, and the adjustment of one's worldview to contain and accept both pre- and post-trauma realities, are crucial for PTG. According to Calhoun and Tedeschi (2006), PTG may include more appreciation for life, increased meaningful interpersonal relationships, higher sense of personal strength, changed priorities, and a richer existential and spiritual life (Calhoun \& Tedeschi, 2006).

Triplett et al. (2011) suggested the possibility that growth can indeed influence well-being positively, but its effects may be primarily indirect. This is an area where findings have been inconsistent at best, and thus require further research on addressing the relationship between PTG and general psychological well-being. To help us understand this more, Tedeschi and Calhoun (1996) spoke of the posttraumatic growth (PTG) as the functional-descriptive model.

According to O'Leary and Ickovics (1995), after experiencing a relatively big trauma, a human person may have different experiences: succumbing (when one is crushed by distress), survival with impairment (partial recovery without attaining pre-event level of functioning), resilience (referring to pre-event level of functioning; the authors here equate this to recovery, although related literature indicate more divergences than otherwise), or thriving (recovery after adverse event, returning to pre-trauma functioning, and even exceeding it on some dimensions).

Factors associated with higher PTG include: a moderate level of adversity, higher social support, cognitive processing of the trauma, self-efficacy, reflection, a search for meaning, and the ability to change core beliefs. On the other hand, factors associated with lower PTG include: brooding, rumination and lower spiritual well-being (Arnold et al., 2005). 
A number of issues have arisen from the PTG literature, namely, what does PTG refer to, is it related to wellbeing, do any factors facilitate its development and what do we mean by growth? Literature and research evidence are mixed when it comes to explaining the link between PTG and wellbeing. Park and Helgeson (2006) mention three main hypotheses that have been put forward, namely: 1) PTG leads to positive life changes and better well-being, 2) PTG leads to life changes which are stressful and therefore, leads to lowered well-being, and 3) PTG is a coping strategy and its effectiveness as a coping strategy mediates the relationship between PTG and wellbeing. Research is inconclusive as to which hypothesis is accurate and so further work is required. The research suggests that 1) victims of trauma are more likely to experience PTG two years after their trauma has occurred (Affleck et al., 1987), 2) people from ethnic minority backgrounds are more able to derive benefit from adversity (Helgeson et al., 2006), and 3) optimism experience more PTG (Milam, 2006). Further research is required to clarify all these findings and understand the mechanisms that underpin the links between PTG and positive outcomes.

Moreover, the literature does not distinguish between PTG as a process or as an outcome, which may have implications for the way PTG research is conducted (e.g. if PTG is an outcome, is it accurate to try to link PTG to other outcomes of trauma such as wellbeing?). Further research is required to clarify these issues. Existing measurement tools such as the Posttraumatic Growth Inventory (Tedeschi \& Calhoun, 1996) do not distinguish between these two types of growth either, so it is very difficult to examine the different ways that PTG may occur. Tedeschi and Calhoun (1996) found that PTG occurs across three domains: interpersonal relationships, self-perception, and life philosophy.

In conclusion, therefore, considering that research on PTG has only really taken off post millennium, the literature covers a vast amount. Research is examining who is most likely to experience PTG, what PTG actually is, what the benefits of PTG are, and how we can facilitate its development. Further research is required in all areas but progress is being made. For the purpose of this study, PTG is understood as finding positive psychological change experienced as a result of trauma or adversity related to fireworks tragedies.

\subsection{Vicarious Posttraumatic Growth (VPTG)}

More complicated may be the possibility of growth through the traumatic event by another person. Present research has mostly focused on vicarious or secondary PTG resulting from experiences by those whose work exposes them to trauma, such as mental health professionals (Engstrom et al., 2008), and emergency services personnel (Shakespeare-Finch et al., 2003), amongst others. There is a growing research base focusing on vicarious PTG among cancer survivors and their families too (Thornton \& Perez, 2006). Vicarious posttraumatic growth (VPTG) refers to the development of positive changes as a result of vicarious 
traumatic exposure (Arnold et al., 2005). Vicarious traumatic exposure has been used in literature to refer to indirect exposure of trauma, such as exposure to direct trauma survivors or the aversive details and logistics of a traumatic incident, rather than exposure to the trauma itself.

Manning-Jones, et al. (2015), in the first comprehensive review of VPTG literature, reviewed 28 articles on the subject. They found that VPTG to be highly similar to direct PTG, albeit with subtle differences.

Lisa (2014) found that personal growth and changes in one's worldview best explained vicarious PTG. While admitting that research into vicarious PTG is limited, Lisa (2014) mentions another context in which this reality has been studied, that is, within families in which one member dies because of an illness. Thornton and Perez (2006) researched growth by prostate cancer survivors and their partners. They suggested that growth is not limited to those directly affected by trauma. It also results among individuals who lose significant others, normally through an illness. Consistent with this, Davis, Nolen-Hoeksema and Larson (1998) also found that vicarious PTG related to better psychological adjustment after trauma. Courtois (2008) defined vicarious trauma as a special form of counter transference stimulated by exposure to the client's traumatic material.

One of the objectives of this study was to assess whether family members exposed to the instant traumatic death of a significant other would report any VPTG as a result. Related literature may shed more light on the nature of dynamics of what may be taking place vis-a-vis the trauma experienced.

This study investigated three aspects of the phenomena under study: 1) the victim (family background, relationship to participant, common experiences), 2) the nature of the tragedy (logistics, time-lapse, memories, how tragedy news broke out, reaction/s of relative, etc.), and 3) the psycho-social and emotional impact of the trauma on the participants.

Studies about the aftermath of fireworks tragedies and the impact on victims' relatives are scarce. However, similar research on vicarious trauma suggests that psychological reactions to the events are not necessarily always negative, but positive experiences are also recorded (Galea, 2014b). These experiences fall within the gamut of post-traumatic growth, whereby individuals may report various personal experiences, and not just the usual negative effects.

\section{Method}

This study was conducted in Malta in 2012. In the last 24 years, there have been 15 fatalities related to fireworks' tragedies. Statistics are skewed because in just 4 years, there were 10 fatalities, and all came from the island of Gozo, with a population of around twenty four thousand inhabitants. Pyrotechnics is a dangerous sport that is complicated not just because it requires professional handlers and manufacturers, but also demands rigorous rules when chemicals are mixed and produced, under stringent conditions. Just to give a simple example, Malta's 
weather (especially the common Southern wind called "Xlokk") is often one reason why certain mixtures in pyrotechnics are not done, due to higher risks of explosion.

In order to understand better the dynamics and processing of relatives who suffered the loss of family members due to fireworks tragedies, we conducted interpretative phenomenological analysis (IPA). A total of 8 individuals met the inclusion criteria and thus were selected for this study. Individuals were personally contacted and interviewed. Data analyzed was according to IPA guidelines.

IPA enables the researcher to reach a deeper understanding of the dynamics, coping strategies, strengths and challenges among relatives stricken by the tragic loss of loved ones due to fireworks accidents. IPA seeks the meaning from ideas emanating from phenomenology, idiography and hermeneutics, based as it is on in-depth analysis of reflective personal accounts and from homogeneous samples. IPA assumes that every individual is equally capable to express themselves. However, results indicate that each person has his or her own way of expressing and explaining their traumatic experience including body language, non-verbal cues, metaphors and emotive language, amongst others (Smith et al., 2011).

Data was collected using in-depth semi-structured questionnaires investigating the subjective experiences and perspectives of close relatives of victims of fireworks tragedies. Questions targeted information about the victim, how the tragedy unfolded, and the aftermath consequences, challenges and potential of growth there from.

Demographic data concerned age of respondent, past and present family situation, children, and future considerations.

\subsection{Participants}

The sample consisted of 8 individuals aged between 18 and 68 years old $(\mathrm{M}=$ 43.87, $\mathrm{SD}=22.64$ ). All were Maltese. Participants included four parents who lost their children, one lost her father, another lost a son and a spouse (during same accident), one who lost a brother and one who lost a relative, all due to firework accidents. Among the victims, four were volunteers were involved in pyrotechnics as a hobby, while the other four did it as their main employment. Two of the victims died alone, while the others died with other colleagues at the scene. The participants' status ranged from being a student (2), housewife (4), self-employed (1) and civil servant (1). Details about the participants' demographics can be seen in Table 1. Seven of the participants were female.

\subsection{Data Analysis}

An average 90 minute semi-structured interview schedule was conducted with each participant, at their place and time of preference. Open-ended questions explored the relationship of participants to their lost relatives, the logistics of the fireworks tragedy, and the after-effects on their well-being and life thereafter.

The interviews were recorded using digital audio equipment and then transcribed verbatim. Data were then analyzed using IPA, according to Smith, 
Table 1. Participants' demographic information.

\begin{tabular}{ccccccc}
\hline \multicolumn{7}{c}{ Demographic Characteristics } \\
\hline Participants & Age & Relation & Time since loss & Status & Nature of tragedy & W/H \\
\hline 1 John & 68 & Parent/M & 2 yrs & C. Servant & Died w 3 others & H \\
2 Debbie & 65 & Parent/F & $2 \mathrm{yrs}$ & Housewife & Died w 3 others & H \\
3 Claire & 16 & Sibling & $2 \mathrm{yrs}$ & Student & Died w 3 others & H \\
4 Mary & 38 & Spouse/F & $3 \mathrm{yrs}$ & Housewife & Died w 5 others & H \\
5 Jane & 58 & Parent/F & $3.5 \mathrm{yrs}$ & Housewife & Died w 5 others & W \\
6 Sarah & 65 & Parent/Sp & $3.5 \mathrm{yrs}$ & Housewife & Died w 4 others & W \\
7 Vicky & 18 & Daughter & $5 \mathrm{yrs}$ & Student & Died alone & W \\
8 Lina & 23 & Daughter & $14 \mathrm{yrs}$ & Shop-owner & Died alone & W \\
\hline
\end{tabular}

$\mathrm{N}=8 . \mathrm{W}=$ Work, $\mathrm{H}=$ Hobby.

Jarman, and Osborn (1999). This follows the idiographic approach whereby interviewees' accounts were read and reread until broad claims representative of the group could eventually be arrived at.

Smith et al. (1999) indicated that the analysis consists of the researcher's own acknowledgment of their own perspectives, which guides a better understanding of the participants' personal sharing and experiences. This is done through the researcher's reflective engagement with the transcripts in view of producing a meaning with respect to the phenomenon under investigation, which is called the interpretive method.

First, multiple reading of each transcript and taking notes. While listening to the audio recordings, pauses, silence and other tone variations were registered, having the potential for further interpretation (Smith et al., 2011).

Secondly, transforming notes into emergent themes. This was done through organization of data, both as a reduction of data technique, but also to focus the text into more coherent and latent thematic analysis. At this stage, the analysis was guided by "meaning units", that is, identifying certain key phrases and metaphors used to help enrich and guide the analysis per se. Thus, meaning units within this context help guide the researcher understand better the worldview of the subject, to reach a logical but more importantly a valid appraisal of what exactly the person is trying to convey.

Clustering the emergent themes brings us to the third stage. Comparisons for similarities and differences are noted, in order to place them in a coherent perspective. This is technically called "mapping". By fitting one theme to another, the researcher through coding will be constructing the world-view of the subject under study.

Finally, comes perhaps the most important step in this process: that of writing the narrative account in a systematic and comprehensive way (Smith et al., 1999).

To minimize researcher bias, participants were given the opportunity to receive a copy of their transcripts, and to validate the content of the interviews. 
Participants' names were changed to ascertain anonymity. All codes and themes were given to a second coder who checked each code and theme with anonymized transcripts. All themes were agreed. Discrepancies found numbered 3\% of the total codes, and a consensus was reached through discussion between the researcher and the second coder.

A summary of themes was sent to all participants after the final interview. They all returned their questionnaires validating both the categories and overall model.

Confidentiality protocols were followed throughout the process. Participants were given codes so that no identifying information was presented, except obviously the nature and time of the tragedy per se. Participants were aware of their rights, freedom of participation, and right to stop their participation at any point in time, with no explanation requested of them. Moreover, psychological service was available, had anyone requested it during the study.

\section{Results}

Three superordinate themes, each with a number of subthemes, were identified from the sharings of these 8 participants. Table 2 presents these results. As with the protocol of IPA, each theme is discussed in this section, supported by key excerpts from the interview data.

Table 2. Summary of sub-ordinate and super-ordinate themes developed from participant's quotations.

\begin{tabular}{|c|c|c|c|c|}
\hline $\begin{array}{l}\text { Number of } \\
\text { Quotations }\end{array}$ & Relevant Quotations & Analyzer's Interpretation & Sub-ordinate Theme & Super-ordinate Theme \\
\hline 35 & $\begin{array}{l}\text { "the speed at which everything } \\
\text { occurred..." }\end{array}$ & $\begin{array}{l}\text { Loss is so sudden, only the } \\
\text { present is ours }\end{array}$ & Fragility of life & \multirow{4}{*}{ Appreciation of Life } \\
\hline 109 & $\begin{array}{l}\text { "It's not easy to reason with them...but } \\
\text { their insensitivity hurts..." }\end{array}$ & $\begin{array}{l}\text { Accept others' obsession w } \\
\text { fireworks, but their insensitivity } \\
\text { hurts }\end{array}$ & Acceptance of Reality & \\
\hline 39 & $\begin{array}{c}\text { "Have lost my legacy..." "it's a lost } \\
\text { battle with them" }\end{array}$ & $\begin{array}{c}\text { Adjustment is key as we cannot } \\
\text { control others. Result: shattered } \\
\text { dreams }\end{array}$ & Letting go & \\
\hline 32 & $\begin{array}{l}\text { "having dependent children, having to } \\
\text { prepare lunches, wash clothes, cook, } \\
\text { and all-that helped distract my } \\
\text { thoughts and keep me going" }\end{array}$ & $\begin{array}{l}\text { Use of coping skills: negative \& } \\
\text { positive ones }\end{array}$ & Moving on & \\
\hline 54 & "we got closer..." & $\begin{array}{l}\text { Challenged to embrace a new } \\
\text { family identity }\end{array}$ & Family Cohesion & \multirow[b]{2}{*}{$\begin{array}{l}\text { Richer Interpersonal } \\
\text { Relationships }\end{array}$} \\
\hline 23 & "never felt abandoned really..." & $\begin{array}{l}\text { Altruistic identity, social } \\
\text { integration, positive } \\
\text { alienation, creativity }\end{array}$ & $\begin{array}{l}\text { Meaningful } \\
\text { interpersonal } \\
\text { relationships }\end{array}$ & \\
\hline 44 & "what helped, was prayer" & $\begin{array}{l}\text { more involvement in } \\
\text { religious rituals, groups } \\
\text { \& pilgrimages }\end{array}$ & Religious coping skills & \multirow[b]{2}{*}{ Spiritual Growth } \\
\hline 57 & $\begin{array}{l}\text { "My faith has empowered me a } \\
\text { lot...somehow, my faith kept me going" }\end{array}$ & $\begin{array}{l}\text { Finding a deeper relationship to } \\
\text { God, which empowers gives } \\
\text { personal strength }\end{array}$ & New relation w God & \\
\hline
\end{tabular}




\subsection{Appreciation of Life}

An inherent part in the grief process and growth from trauma refers to appreciation of life. Despite the shock and dramatic loss involved in such situations, appreciation of life becomes a key ingredient. In view of life's finiteness, one surely is moved not to take own life for granted, but tries to cease and cherish each moment to the best of own ability. Four subthemes emerged from this study, namely a) fragility of life; b) acceptance of reality despite others' obsession with fireworks and insensitivities, c) letting go, and d) moving on with life.

Fragility of life. Most of the participants shared the fact that they were awestruck by the suddenness at which events unfolded during their tragic events. Mary recalled how she was still tormented "at the speed at which everything occurred..." She continued that:

"Life is too short. I used to think that our life is just given to us for a set period of time. But after the tragedy, I started appreciating more what I have... in one second, your world will turn upside down..."

Research on grief indicates that when tragedy strikes, those impacted by it are left in shock and denial (Kubler-Ross \& Kessler, 2014). Among the aspects that were highlighted from these relatives, we find: memories of shock and disbelief, vulnerability and loneliness, and challenges in moving on. Jane reiterated that to her, life stopped on the day of tragedy, thus losing all enthusiasm in life: “...do you blame me? He is now gone, forever."

To stress this aspect, Lina recalls an image that comes to mind each time she remembers her father: that of an empty hole which could never be filled up (by no one else). The void left behind is satisfied by no one. Obviously certain times, like birthdays and family occasions, make the loss harder still.

Tragic occasions have the potential to challenge our inner beliefs and bring us face to face with our finiteness (Galea, 2006). Participants repeated the loneliness and void that their respective losses brought upon them. To Sarah, the days after the tragedy were very lonesome, despite being surrounded by family and friends: “...surrounded by people, but strangely enough still lonely, wondering on my own..." Having suffered another explosion with no casualties, Sarah now feels that the present one, having lost her husband and two children, is surely the last straw of the burden she could carry!

Acceptance of reality (despite others' Obsessions and Insensitivities). As described over and over again, firework-manufacturing seems to carry an innate obsession on those involved in it. During this study, fireworks were described as "obsession", "drug", "passion", "addiction", and even "life's true love", by respondents.

John, who lost his son, described pyrotechnics as (his son's) “..childhood passion....and his main objective in life...” Surviving three prior related accidents, he still persisted in his hobby. He was so obsessed by it, that he even put it before his love life-in fact, he never had a steady relationship despite being at the prime of life. Vicky, on her part, opined that "despite having little children, (her 
husband) pursued with his hobby nevertheless...they seem to see nothing else except their obsession with fireworks...”. To most, it seems that their real pay is the personal satisfaction when it is let off-something quite difficult to comprehend by their families.

The appeal of pyrotechnics was at times maintained and covered up by lies, as Sarah mentioned. In Jane's case, her husband tried on several occasions to water down the risks involved. Most believed that it was easier to die in a traffic accident than in a firework incident.

It is understandable that one be troubled by a degree of guilt. However, despite the fact that all participants did try to convince their relatives to quit repeatedly, their warnings failed. Debbie summarized it succinctly: "we cannot understand it...their passion is only logical to them...to us it's mere foolishness, a waste of life..." Jane agreed with this line of thought. She felt that her son died doing what he honestly enjoyed doing.

Insensitivity hurts. Another related issue regards insensitivity. Most participants felt deeply hurt and angered by the apparent insensitivity of their relatives to their repeated warnings. Vicky:

"..it's not easy to reason with them...but they need to remember the price that relatives pay...it's a no win situation for us, their families: we worry for their safety all the time, and if tragedy occurs (as it did with mine), we live condemned...yes, their insensitivity hurts deeply..."

Being fully licensed, having experience and using due diligence are three key safety ingredients when manufacturing fireworks. However, they are not enough! As Sarah clearly emphasized, “...one's carefulness won't make up for others' mistakes... if one is blown up, all around will perish...but it hurts knowing that my warnings fell on deaf ears..."

Insensitivity may result also during the aftermath of tragedy. Mary narrated in detail that her tragedy was twofold: the tragic loss of her husband and the way she was treated in hospital. Although naturally his death distraught her, the apparent insensitivity of some hospital staff (towards her), was too much to bear during that tragedy: “...losing my husband was bad enough...but to have insensitive hospital staff... was something I still cannot digest... that hurts...I still cannot forgive them..."

Letting go. A key aspect in the mourning process is that of letting go. It is the hard truth of life that to grow, one must let go (of things and people). Judith Viorst (2003) explains that this is the ingredient to help a person grow, from an infant to a child, to an adolescent, and on to an adult. No matter how much one strives to retain to past childhood dreams, unless it is forsaken, one cannot earnestly grow further in life. This is also the case when a person is grieving the loss of someone significant in one's life. Jane summed it up succinctly: “...no matter what you tell your children, they will eventually do what they want to do." Such tragedies defy normal expectations where adults die before their children. For this reason, Debbie felt that no closure ever seems enough. 
Letting go involves the experiencing of shattered assumptions and dreams in life. Jane clarified that "my biggest dream was shattered... was of meeting him again, but that is gone, period..." To Sarah, the letting go experience meant drastically altering one's dreams and expectations.

Experience and time seems to have taught the participants to move on and somehow let go of the past. The process of letting go involves also seeking a new meaning in life in light of one's trauma. Jane recalled that nothing of that magnitude ever occurred in her life before: "...his absence is very dramatic, very bold...once you have him, once you don't, is unbelievably hard... Even losing an infant, is hard, let al. one a young man..." Lina recounted that whenever similar tragedies occur, she is overcome by many horrible feelings and memories...

"...But then again, those who work in fireworks know very well of the high risks involved. Adult relatives feel much worse in such times than little ones, as I was..."

Letting go may involve learning new hobbies, seeking new relationships and adjusting to new routines. Mary opined that “...it was a lost battle trying to convince him to quit that hobby...true, time heals, or rather you learn to get distracted..."

Moving on. Participants were also queried on how their trauma following the loss of their loved ones affected their lives. Naturally, responses varied, as expected, from positive growth (social support and coping skills), to mere existence and despair.

To young Claire, who was 15 at the time, the death of her older brother instilled in her more appreciation and carefulness in life. She learned to treasure each moment.

A common thread was that relatives were offered support and assistance. However, that was often not enough. Digesting and processing the tragic and dramatic loss, and adjusting to life after death, was a challenge each had to face on their own. Some acknowledged the generosity of friends, while others were left to fend on their own. As always, some (Mary and Sarah) even recounted how they were misunderstood by others and prejudged for what they did to move on.

When facing tragedy, each person has their own particular coping skills, and each family her own dynamics in facing such troubling and sudden traumas. To some, they prefer to ignore it, not to open past wounds, as in Jane's case: "...however, as a family, we never mention him. He remained our greatest secret...our elephant in the room... to each his own...that remains our weakest point still..."

Lina recounted that being still young at the time of tragedy, her family tried to shield her by not talking and expressing emotions in her presence. However, there were times that she wanted to ask her mother many troubling questions. Ironically, each member kept their feelings and troubling questions at bay. Lina learned to suppress her feelings as well to move on:

“...the loss left enough trouble and pain in my family... no one wanted to in- 
crease it... I learned to hide it...but secretly I retained many newspaper bits with stories about my father's tragedy..."

Moving on does not always imply positive adjustment. Sarah confided that she is "...always depressed, and frequently cry, alone... other tragedies open up past wounds, it s awful... (crying)" To add insult to injury, her daughter recently confided in her: “..' mom, I now believe that he won't ever come, since he didn't come yet..." She was somehow still expecting him back!

Having dependents may be both an advantage and disadvantage. Jane found that having dependents meant more challenges in life. Although at first, she found temporary solace in anti-depressants, she had to face the hard facts of life and attend to her dependents' needs: “...it's hard to help dependents when no one attends to your brokenness..." Agreeing with this line of thought, Mary reiterated that she hit the ground running after the tragic loss of her husband: "...having dependent children, having to prepare lunches, wash clothes, cook, and all-that helped distract my thoughts and keep me going... in a way..." Moving on may also mean growing further. Lina opined that the tragedy, if anything, assisted her to become more independent in life, even though acknowledging the fact that her father won't be present to her upcoming marriage: "what changed? I became more independent... like I matured before my time. I had to fend on my own, because there was no father to protect me..."

However, one thing is clear: moving on and positively adjusting always comes at a price. Life is never meant to be an easy ride. Moving on to some may be a slow and a delicate shift from ruminating why me?, to accepting new challenges as new opportunities of growth. Mary explained that moving on with life, after such an ordeal, is harder still:

“This year I experienced 2 miscarriages. ...why? Why this pain again? (pause) ...true, but it's better to realize that such is life and move on...it's not easy to address grief alone, let al.one to help your dependents as well... deep down I was torn apart... the challenge is that life moves on-and thank God for that. Hard as it may be, some routine will eventually be born again...he is gone, but we moved on, and are maturing from it...”

\subsection{Richer Interpersonal Relationships}

Suffering can lead a person to turn negative and detach from others or it can open one to become more altruistic, empathic, and understanding. Looking outside oneself requires that a person pushes own limits towards the unknown, learns to be creative, and does not get stuck within oneself. Of course, this comes at a price. Sarah explained that some occasions still remain: “...a chore, even going to grocery at times, but I have to force myself... (crying)". Forcing herself helped her move on and establish a new routine in life. Sub-themes under this domain included: altruistic identity, and meaningful interpersonal relationships.

Altruistic identity. Evident mostly among participants (John, Debbie, Mary, Jane and Sarah) who had dependents at the time of tragedy. In different ways, 
the trauma impelled them to focus on the needs of their young ones, more than on their own. Although this increased pressures and stress on them, it did serve as a positive alienation and somehow assisted them in the healing process and growth.

Another common variable amongst many participants in such tragedies is the family component. John and Debbie, shared their experiences on how their tragedy somehow resulted in more cohesion in their family, despite the void and emptiness. John said that his: "family became more united...and we focused more on our two other children, on their school work, their well-being..."

The participants explained that the tragedy of loved ones brought about lots of changes and adjustments. To some, it shook even the foundations of families and caused friction, as narrated by Jane: "...eventually we realized it was all futile (to keep arguing), ...only then we got closer...” To others, it caused other changes, as spelled out by Sarah: "...I turned my home into a shrine in his honor at first, hung his pictures in each room...lit candles...but eventually, I removed it all...my younger son could not stand it any longer...now, things are better... as a family, I believe we became closer..."

Meaningful interpersonal relationships. The help offered at the time of tragedy, and its aftermath, was varied. Some acknowledged the generosity of many around them, while others were left to fend on their own. Jane's experience was mixed: "...I found lots of assistance through family and close friends, even financial help... but still I had to learn to face my daily battles, on my own steam..." Sarah was also assisted financially which was well appreciated at the time. In hindsight though, she preferred social support than monetary donations: “...after all, financial donations can be an easy way to quiet one's conscience in view of others' suffering?' For example, some of her friends distanced themselves after the tragedy. To her it was another blow, even though she sometimes excuses them: "...after all, not everyone is comfortable addressing sheer tragedy and pain."

For Lina, after the initial shock, the tragedy produced a new energy and positivity. She learned to suppress her feelings and move on "...the tragedy infused a new energy in our family... I never felt abandoned really...my eldest brother took particular care of me...soon enough, we all started working...that was a good positive alienation..." Jane and Vicky established new routines. Vicky described how creating other friendships, even through her parish, helped her expand her social network. She felt that it was positive alienation which worked quite well to her. She enthusiastically shared that: “... new friendships, and joining a crafts-class, helped me alienate myself positively...addressed my emptiness... keeping busy helped me stay focused and be altruistic...". Mary has established a new relationship. There are instances when a person finds secret solace and an interesting positivity is born. Mary opined:

"I found it hard to enter church at first...but God did bring into our lives another person, another partner to me, a second father to my children, who 
loves them dearly...even though the void left by my husband will remain for ever with us..."

\subsection{Spiritual Growth}

Tragedies tend to make us question our faith, evaluate our existential priorities in life, and somehow enable us to reorganize what we value in life. Spiritual growth is broken down into religious coping skills and a new relationship with God.

Religious coping skills. To many, religion offers coping mechanisms and ways to deal with a number of doubts. Vicky noted that: "what helped was prayer, my spirituality... it took months for me to get some normalcy though..., I had to force myself... (crying)... but it works"

Religious coping skills may translate into rituals and pilgrimages, as in the case of Sarah:

"...my faith, believing in God, in the virgin Mary...I did go to Medjugorje... three times...in my prayers I sought to know where they (my sons) are now...I believe that they are at peace. It took lots of crying and praying though..."

New relationship with God. Debbie had undergone normal doubts about her faith: “...where was our God in all this?" Although she believes that she has moved on forward with faith, she still harbors at times troubling and existential questions as to why certain events occur. Jane believed that she has grown in faith, even though doubts have never ceased:

“...even my belief has now changed or rather matured...maybe before I took things for granted...not anymore, my faith goes through highs and lows...my son is gone, for ever...but his memory, his voice lives on within..."

Faith seemed responsible to help and empower a number of participants to find strength and move on, despite their tragic loss. Mary clarified that having faith was crucial to her, to keep moving on, despite all existential doubts: “...at first, yes, I was angry at God...religion was responsible somehow... (husband died while preparing for a religious festa), I found it hard to enter church...my children lost their loving father. But God did bring us another loving person, partner to me and a second father to my children, who loves them dearly..."

Lina felt that faith played a major role in her coping skills and ability to grow spiritually:

"My faith has empowered me a lot...somehow, my faith kept me going. My father was gone, but his spirit lived on within...I do feel that I have also grown in my spirituality... I mean I don't take things and life in general for granted now. It $s$ a more mature, deeper and grounded faith..."

Another young participant at the time, Claire, shared how the loss of her big brother initiated in her an urgency to make spirituality more relevant in life. This resulted in appreciating life more. To Mary, the tragic loss of her husband encouraged her to face her daily challenges squarely and in so doing, she became a stronger person: 
“...God gives me the push to face any challenges that come my way. I survived my husband s tragic death, and am sure I can survive anything... in this respect I strongly believe that my God is closer to me and my pain, much closer, than... before..."

Summing up this section was perhaps Mary comment, that at hindsight, she believes that: "... this suffering primed me to have a different relationship with my God...now I believe in a God who is closer to me, and whom I can see more down to earth...I have learned to remove empty childhood expectations...then I was more entitled...now I live life day by day, and moment by moment..." Suffering can indeed bring out the worst or the best in a human person!

\section{Discussion}

The primary purpose of this research was to examine the varied effects of vicarious trauma and lived experiences of participants who lost relatives and family members to firework tragedies in Malta. It is to be expected that traumatic tragedies result in highly negative impact on both the surviving victims, and their relatives. Of interest to this study were the dynamics on how a very negative tragedy can in effect have positive consequences as well among relatives after suffering the loss of their family members, and how they could be life-changing. As Thornton and Perez (2006) found, post-traumatic growth occurs also among relatives of individuals who die from a traumatic event, and not just in victims only. This study identified three superordinate themes: 1) appreciation of the here and now; 2) more meaningful relationships; and 3) spiritual growth. These themes are according to Tedeschi and Calhoun's latent dimensions (2004).

Appreciation of life considers the recognition and acknowledgement of the here and now. Four sub-themes highlighted this super-ordinate theme: first, fragility of life. This included the sheer suddenness of their tragic trauma and the realization that the present is really the only time available to one and all. Secondly is acceptance of reality. In this study, participants had to accept the reality of their loved ones' obsessions with fireworks, despite their warnings. To add to this, their obsessions led to perceived insensitivity to these participants' worries and loving concerns. Some victims even went to great lengths (lying and excuses) to maintain their hobby. Third, letting go experience, which includes: letting go of our control over own children's values and future pursuits, shattered dreams (about their future), and adjusting to new realities while learning new lifestyles and hobbies. Finally, appreciation of life translated into moving on with one's life, through social support and other coping skills. For some, this had a negative connotation (denying reality or seeking anti- depressants to cope); yet for others it meant positive alienation, a way to grow further.

Carver et al. (2002) clarify that in such reports, it is often the case of changed priorities in life as well. Whatever goals were adhered to pre-trauma, the adjustment to the aftermath may also include a broader spectrum, with a particular focus on the here and now reality. Considering the three main hypotheses being 
researched in related literature, as cited by Park and Helgeson (2006), it seems that this study relates to some respects to all three hypotheses mentioned. This study in fact considered some participants in viewing VPTG as enriching well-being through positive life changes, others who experienced VPTG as a stressful reality that lowers well-being, and yet others who perceived growth as a coping strategy. What seems clear though is that as pain and suffering are a different reality to each individual, despite similarities in the events and the people themselves, so also post-traumatic growth seems to have a unique meaning to those experiencing it. To this effect, a person may find growth from trauma as a positive life changer, but still encounter it as very stressful.

More meaningful interpersonal relationships resulted in two sub-themes: first, family cohesion, including a new family identity; and secondly, richer interpersonal relationships, which is highlighted by an altruistic identity, social integration, creativity and positive alienation. Obviously, social support may not always produce positive results. As suggested by Ingram et al. (2001), more researchers are highlighting the fact that more work is required regarding the differences between positive and negative aspects of social support and interpersonal relationships.

Spiritual growth was the final superordinate theme of this study's interpretative results. Studies have shown that struggling with trauma can deepen one's self-transcendence, spirituality and religious beliefs (Galea, 2010, 2008). Spiritual growth included two sub-themes: first, religious coping skills which included more involvement in one's religion, through rituals and pilgrimages; and secondly, a new relationship with God which results in empowerment and personal strength to become a stronger person. Spirituality and religion are increasingly cited to have big importance in adaptation and adjustment, particularly after trauma (Calhoun et al., 2000; Overcash et al., 1996; Weaver et al., 2003; Galea, 2007, 2012c, 2014c).

In line with this, a growing body of research is suggesting that individuals who experience PTG may not necessarily experience less pain nor an increase in their happiness (Janoff-Bulman, 2006; Galea, 2014d; Tedeschi \& Calhoun, 2004; Tugade \& Fredrickson, 2004). It is evident that more research is required on these correlations. In fact, Park \& Helgeson (2006) found that there is inconsistent research data on the relationship between PTG and psychological comfort.

This study has found that one important super-ordinate theme highlighted is that of appreciation of life. Breaking down this super-ordinate theme provides a clearer picture that growth to these participants does not simply mean a naive sense of a better or happy life. Surely, reality is not that straightforward. Results suggest that for these participants, going through the traumatic loss of their loved ones means acknowledging life's vulnerability, in that one accident may change the whole spectrum of one's life. As one participant said, it takes just one second! Furthermore, this also includes accepting others' decisions which may not reflect one's own. Life is full of adjusting our own expectations to the reality around which may not be in synch with our own priorities. Accepting the reality 
of life involves letting go of one's dreams, expectations and one's perceived control over others. Only finally can one reach the last aspect of appreciating life, that of moving on with one's life.

This study has spelled out that appreciation of life includes a number of necessary albeit difficult steps of the experience of pain, in the process of one's own transformation. PTG does not necessarily refer to growth as a carefree, happy, or feeling good. As King et al. (2004) asserts, living one's life at a deeper and more meaningful level of personal, interpersonal and spiritual awareness is not necessarily the same as feeling good!

\section{Limitations and Future Directions}

Although offering some intriguing findings and suggesting areas for further inquiry, this study has some limitations as well. It was based on self-report data by participants who suffered their traumas around 2 years or more prior the interviewing. Some ways in which biases may contaminate reports of growth are: social desirability, biases in cognitive reconstruction, downward comparisons and effects of subsequent events and interactions (Pyszczynski \& Greenberg, 1992).

That literature about PTG experiences are not limited to traumatized individuals only, but also extended to their significant others, family members and close friends is increasingly being manifested in lots of research, as mentioned earlier. Much of this literature concerns cancer-survivor research and their families (Manne et al., 2004). However, this present study continues to extend research on vicarious PTG beyond cancer-related studies, to other traumas as well. Moreover, the fact that such conclusions resulted from a new culture to related research found elsewhere is another plus. Recognizing psychological, social and culturally-related PTG is important-an area that continues to require further investigation.

Of the implications for health and pastoral workers when facing tragedies of this nature, we need to recommend: a) the ongoing and long term attention to families struck by such fireworks trauma. This is more critical considering that consequences (and life in general) normally become more complex as time moves on. It is evident that assisting such families immediately after trauma, and later on, require different help-modalities altogether; and b) although financial assistance remains always beneficial, as results suggest, it can never replace true social support.

\section{Conclusion}

Positive achievements in PTG are outcomes that result from this Maltese study. This study adds to the increasing research on vicarious PTG, not only among cancer-related survivors and their families, but also to families who lost loved ones in fireworks tragedies, and in a different culture. Highlighted themes in this study are generally according to Tedeschi and Calhoun's theory of post-traumatic growth. Positive achievements are instrumental in enriching the qualitative and 
quantitative reality of life among relatives of pyrotechnics' tragedies. All caregivers are asked to attend more to this enhancement.

\section{References}

Affleck, G., Tennen, H., Croog, S., \& Levine, S. (1987). Causal Attribution, Perceived Benefits, and Morbidity after a Heart Attack: An 8 Year Study. Journal of Consulting and Clinical Psychology, 55, 29-35. https://doi.org/10.1037/0022-006X.55.1.29

Arnold, D., Calhoun, L. G., Tedeschi, R., \& Cann, A. (2005). Vicarious Posttraumatic Growth in Psychotherapy. Journal of Humanistic Psychology, 45, 239-263. https://doi.org/10.1177/0022167805274729

Calhoun, L. G., \& Tedeschi, R. G. (2006). The Foundations of Posttraumatic Growth: An Expanded Framework. In L. G. Calhoun, \& R. G. Tedeschi (Eds.), Handbook of Posttraumatic Growth: Research and Practice (pp. 1-23). Mahwah, NJ: Erlbaum.

Calhoun, L., Cann, A., Tedeschi, R., \& McMillian, J. (2000). A Correlational Test of the Relationship between Posttraumatic Growth, and Cognitive Processing. Journal of Traumatic Stress, 13, 521-527. https://doi.org/10.1023/A:1007745627077

Carver, C. S., \& Scheier, M. F. (2002). Three Human Strengths. In L. G. Aspinwall, \& U. M. Staudinger (Eds.), A Psychology of Human Strengths, Fundamental Questions and Future Directions for a Positive Psychology. Washington DC: American Psychological Association.

Courtois, C. A. (2008). Complex Trauma, Complex Reactions: Assessment and Treatment. Psychological Trauma: Theory, Research, Practice, and Policy, No. 1, 86-100. https://doi.org/10.1037/1942-9681.S.1.86

Davis, C. G., Nolen-Hoeksema, S., \& Larson, J. (1998). Making Sense of Loss and Benefiting from the Experience: Two Construals of Meaning. Journal of Personality and Social Psychology, 72, 561-574. https://doi.org/10.1037/0022-3514.75.2.561

Engstrom, D., Hernandez, P., \& Gangsei, D. (2008). Vicarious Resilience: A Qualitative Investigation into Its Description. Traumatology, 14, 13-21.

https://doi.org/10.1177/1534765608319323

Galea, M. (2006). Kuraggbiexnikber. Gozo: J deBono Press.

Galea, M. (2010). Does Child Maltreatment Mediate Family Environment and Psychological Well-Being? Psychology, 1, 143-150.

Galea, M. (2012c). Integrating Spirituality with Positive Psychology in View of Childhood Trauma. In C. A. Stark, \& D. C. Bonner (Eds.), Handbook on Spirituality: Belief Systems, Societal Impact and Roles in Coping (Vol. 4, pp. 85-106). NOVA Publishers.

Galea, M. (2014b). The Relationship of Personality, Spirituality, and Posttraumatic Growth to Subjective Wellbeing. Open Access Library Journal, 1-10. https://doi.org/10.4236/oalib.1101069

Galea, M. (2014c). Modeling the Relationship between Personality and Posttraumatic Growth. In A. Haddock, \& A. Rutkowski (Eds.), Psychology of Extraversion. NOVA Publishers.

Galea, M., Ciarrocchi, J. W., Piedmont, R. L., \& Wicks, R. J. (2008). The Impact of Child Abuse on the Psycho-Spiritual and Religious Status of Maltese College Students. Pastoral Psychology, 57, 147-159. https://doi.org/10.1007/s11089-008-0159-5

Galea, M., Ciarrocchi, J. W., Piedmont, R. L., \& Wicks, R. J. (2007). Child Abuse, Personality, and Spirituality as Predictors of Happiness in Maltese College Students. Research in the Social Scientific Study of Religion, 18, 141-154.

https://doi.org/10.1163/ej.9789004158511.i-301.57 
Helgeson, V. S., Reynolds, K. A., \& Tomich, P. L. (2006). A Meta-Analytic Review of Benefit Finding and Growth. Journal of Consulting and Clinical Psychology, 74, 797-816. https://doi.org/10.1037/0022-006X.74.5.797

Ingram, K. M., Betz, N. E., Mindes, E. J., Schmitt, M. M., \& Smith, N. J. (2001). Unsupportive Responses from Others Concerning a Stressful Life Event: Development of the Unsupportive Social Interactions Inventory. Journal of Social and Clinical Psychology, 20, 173-207.

Janoff-Bulman, R. (2006). Schema-Change Perspectives on Posttraumatic Growth. In L. G. Calhoun, \& R. G. Tedeschi (Eds.), Handbook of Posttraumatic Growth: Research and Practice. Mahwah, NJ: Erlbaum.

King, L. A., Eells, J. E., \& Burton, C. M. (2004). The Good Life, Broadly and Narrowly Considered. In A. P. Linley, \& S. Joseph (Eds.), Positive Psychology in Practice. New York, NJ: Wiley.

Kubler-Ross, E., \& Kessler, D. (2014). Finding the Meaning of Grief through the Five Stages of Loss. On Grief and Grieving. London: Simon \& Schuster.

Lisa, A. (2014). Vicarious Posttraumatic Growth: Predictors of Growth and Relationships with Adjustment. Traumatology, 20, 9-18.

Manne, S. L., Ostroff, J. S., Sherman, M, Heyman, R., Ross, S., \& Fox, K. (2004). Couples' Support-Related Communication, Psychological Distress, and Relationship Satisfaction among Women with Early Stage Breast Cancer. Journal of Consulting and Clinical Psychology, 72, 660-670. https://doi.org/10.1037/0022-006X.72.4.660

Manning-Jones, S., Terte, I., \& Stephens, C. (2015). Vicarious Posttraumatic Growth: A Systematic Literature Review. International Journal of Wellbeing, 5, 125-139. https://doi.org/10.5502/ijw.v5i2.8

McMillen, C., Zuravin, S., \& Rideout, G. (1995). Perceived Benefits from Child Sexual Abuse. Journal of Consulting and Clinical Psychology, 63, 1037-1043.

Milam, J. E. (2006). Posttraumatic Growth and HIV Disease Progression. Journal of Consulting and Clinical Psychology, 74, 817-827. https://doi.org/10.1037/0022-006X.74.5.817

Muscat, C. (2014). Fireworks Must Be Reduced for Health. https://www.timesofmalta.com/articles/view/20140615/local/Fireworks-must-be-reduc ed-for-health-.523376

O'Leary, V., \& Ickovics, J. R. (1995). Resilience and Thriving in Response to Challenge: An Opportunity for a Paradigm Shift in Women's Health. Women's Health: Research and Gender, Behavior and Policy, 1, 121-142.

Overcash, W. S., Calhoun, L. G., Cann, A., \& Tedeschi, R. G. (1996). Coping with Crisis: An Examination of the Impact of Traumatic Events on Personal Belief Systems. Journal of Genetic Psychology, 157, 455-464.

Pargament, K. I. (1997). The Psychology of Religion and Coping. In Theory, Research and Practice. New York, NY: Guilford Press.

Park, C. L., \& Helgeson, V. S. (2006). Introduction to the Special Section: Growth Following Highly Stressful Life Events-Current Status and Future Directions. Journal of Consulting and Clinical Psychology, 74, 791-796. https://doi.org/10.1037/0022-006X.74.5.791

Park, C., Cohen, L., \& Murch, R. (1996). Assessment and Prediction of Stress-Related Growth. Journal of Personality, 64, 71-105.

Pyszczynski, A., \& Greenberg, J. (1992). Hanging on and Letting Go: Understanding the 
Onset, Progression, and Remission of Depression. New York, NY: Springer.

Ryff, C. D., \& Singer, B. (1998). The Role of Purpose in Life and Personal Growth in Positive Human Health. In P. T. P. Wong, \& P. S. Fry (Eds.), The Human Quest for Meaning: A Handbook of Psychological Research and Clinical Applications (pp. 213-235). Mahwah, NJ: Lawrence Erlbaum Associates, Inc.

Shakespeare-Finch, J. E., Smith, S. J., Gow, K. M., Embelton, G., \& Baird, L. S. (2003). The Prevalence of Posttraumatic Growth in Emergency Ambulance Personnel. Traumatology, 9, 58-70. https://doi.org/10.1177/153476560300900104

Smith, A., Joseph, S., \& Dar Nair, R. (2011). An Interpretative Phenomenological Analysis of Posttraumatic Growth in Adults Bereaved by Suicide. Journal of Loss and Trauma, 16, 5. https://doi.org/10.1080/15325024.2011.572047

Smith, J. A. (1999). Identity Development during the Transition to Motherhood: An Interpretative Phenomenological Analysis. Journal of Reproductive and Infant Psychology, 17, 281-300. https://doi.org/10.1080/02646839908404595

Smith, J. A., Jarman, M., \& Osborne, M. (1999). Doing Interpretative Phenomenological Analysis. In M. Murray, \& K. Chamberlain (Eds.), Qualitative Health Psychology: Theories and Methods. London: Sage. https://doi.org/10.4135/9781446217870.n14

Tedeschi, R. G., \& Calhoun, C. G. (2004). Posttraumatic Growth: Conceptual Foundations and Empirical Evidence. Psychological Inquiry, 15, 1-18. https://doi.org/10.1207/s15327965pli1501_01

Tedeschi, R. G., \& Calhoun, L. G. (1996). The Posttraumatic Growth Inventory: Measuring the Positive Legacy of Trauma. Journal of Traumatic Stress, 9, 455-471. https://doi.org/10.1002/jts.2490090305

Tedeschi, R. G., \& Calhoun, L. G. (2004). A Clinical Approach to PTG. In A. P. Linley, \& S. Joseph (Eds.), Positive Psychology in Practice. New York, NJ: Wiley.

The Malta Independent (2012). Number of Fireworks Related Accidents Shocking. http://www.independent.com.mt/articles/2012-02-17/news/number-of-fireworks-relate d-accidents-shocking-305931/

Thornton, A. A., \& Perez, M. A. (2006). Posttraumatic Growth in Prostate Cáncer Survivors and Their Partners. Psycho-Oncology, 15, 285-296. https://doi.org/10.1002/pon.953

Times of Malta (2009). Fireworks Displays Get Bigger and More Costly. https://www.timesofmalta.com/articles/view/20090814/local/firework-displays-get-bigg er-and-more-costly.269443

Triplett, K. A., Tedeschi, R. G., Cann, A., Calhoun, L. G., \& Reeve, C. L. (2011). Posttraumatic Growth, Meaning in Life, and Life Satisfaction in Response to Trauma. Psychological Trauma, Theory, Research, Practice and Policy, 1, 400-410. https://doi.org/10.1037/a0024204

Tugade, M. M., \& Fredrickson, B. L. (2004). Resilient Individuals Use Positive Emotions to Bounce Back from Negative Emotional Experiences. Journal of Personality and Social Psychology, 86, 320-333.

TVM News (2017). Unfortunate Pattern of Fireworks Tragedy Every Two Years Has Been Broken.

https://www.tvm.com.mt/en/news/unfortunate-pattern-of-fireworks-tragedy-every-tw o-years-has-been-broken/

Viorst, J. (2003). Necessary Losses. New York: Fireside.

Weaver, A. J., Samford, J. A., Morgan, V. J., Lichton, A. I., Larson, D. B., \& Garabrino, J. (2003). Research on Religious Variables in Five Major Adolescent Research Journals: 1992-1996. Journal of Nervous and Mental Disorders, 188, 6-44. 